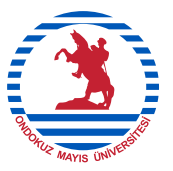

Samsun Sağlık Bilimleri Dergisi,

Journal of Samsun Health Sciences

ISSN: 2458-8857 e-ISSN: 2791-972, JSHS December 2021, 6(3): 541-556

\title{
Covid-19 Salgınında Ebelik Öğrencilerinin Siberkondri Düzeyleri ve Etkileyen Faktörlerin İncelenmesi
}

Investigation of Cyberchondria Levels and Affecting Factors of Midwifery Students in the Covid-19

Pandemic

Yasemin AYDIN KARTAL ${ }^{1}$, Leyla KAYA²

1 Sağlık Bilimleri Üniversitesi, Hamidiye Sağlık Bilimleri Fakültesi, Ebelik Bölümü

•yasemin.aydin@sbu.edu.tr • ORCID > 0000-0001-7464-945X

${ }^{2}$ Sağlık Bilimleri Üniversitesi Zeynep Kamil Kadın ve Çocuk Hastalıkları Eğitim ve Araştırma Hastanesi •leylakaya02@hotmail.com•ORCiD > 0000-0002-2199-0854

Makale Bilgisi / Article Information

Makale Türü / Article Types: Araştırma Makalesi / Research Article

Geliş Tarihi / Received: 19 Temmuz / July 2021

Kabul Tarihi / Accepted: 10 Kasım / November 2021

Yıl / Year: 2021 | Cilt - Volume: 6 | Sayl - Issue: 3 | Sayfa / Pages: 541-556

Atıf/Cite as: Aydın Kartal, Y. ve Kaya, L. “Covid-19 Salgınında Ebelik Öğrencilerinin Siberkondri Düzeyleri Ve Etkileyen Faktörlerin Incelenmesi - Investigation of Cyberchondria Levels and Affecting Factors of Midwifery Students in the Covid-19 Pandemic ". Samsun Sağlık Bilimleri Dergisi- Journal of Samsun Health Sciences 6(3), Aralık 2021: 541-556. https://doi.org/10.47115/ jshs.969748

Sorumlu Yazar: Yasemin AYDIN KARTAL

Copyright @ Published by Ondokuz Mayıs Üniversitesi, Sağlık Bilimleri Fakültesi - Ondokuz Mayıs University, Faculty of Health Sciences, Samsun, Turkey. All rights reserved. 


\section{COVID-19 SALGININDA EBELIK ÖĞRENCILERINNIN SIBBERKONDRI DÜZEYLERI VE ETKILEYEN FAKTÖRLERIN INCELENMESI}

\section{ÖZ:}

Amaç: Bu çalışma, Covid-19 salgınında ebelik öğrencilerinin siberkondri düzeyleri ile etkileyen faktörlerin belirlenmesi amacıyla yürütülmüştür.

Yöntem: Tanımlayıcı desende yürütülen çalışmanın örneklemini, bir kamu üniversitesinin Sağlık Bilimleri Fakültesi Ebelik Bölümü’nde öğrenim gören 308 öğrenci oluşturdu (Katılma Oranı: \%93). Çalışmaya katılmayı kabul eden öğrencilere, "Kişisel Bilgi formu” ve "Siberkondri Ciddiyet Ölçeği (SCÖ)" uygulandı.

Bulgular: Araştırmaya katılan öğrencilerin yaş ortalamasının 20.96 \pm 2.56 olduğu belirlendi. Ebe adaylarının \%14.6'sı Covid-19 enfeksiyonu tanısı aldığı, \%71.8’i Covid-19 geçiren birey ile temas ettiği ve \%36.7'sinin ailesinde Covid-19 tanısı alan birey olduğu saptandı. Öğrencilerin SCÖ toplam puan ortalamasının 77.44 23.01 olduğu saptandı. Öğrencilerin sınıf düzeyi, sigara kullanma durumu, kronik hastalık varlığı, Covid-19 enfeksiyonu geçirme ve ailesinde Covid-19 enfeksiyonu geçiren birey varlığı durumunun SCÖ puanlarını anlamlı olarak farklılaştırdığ belirlendi.

Sonuç ve Öneriler: Çalışmaya katılan öğrenciler orta düzeyde siberkondriye sahip oldukları belirlendi. Sınıf düzeyi, sigara kullanma durumu, kronik hastalık varlığı, Covid-19 enfeksiyonu geçirme ve ailesinde Covid-19 enfeksiyonu geçiren birey varlığı gibi değişkenlerin siberkondri davranışının önemli yordayıcıları olduğu belirlendi. Ebelik öğrencilerinde siberkondriyi en aza indirmek için, artan tehdit algısı ele alınarak ve belirsizlik yönetimi ve çevrimiçi sağlık bilgisi okuryazarlığı geliştirilerek bu yeni tehlikeyle mücadele için etkili bir plan geliştirilmelidir.

Anahtar Kelimeler: Ebelik; Öğrenciler; Covid-19; Siberkondri; Pandemi

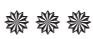

\section{INVESTIGATION OF CYBERCHONDRIA LEVELS AND AFFECTING FACTORS OF MIDWIFERY STUDENTS IN THE COVID-19 PANDEMIC}

\section{ABSTRACT:}

Aim: This study was carried out to determine the cyberchondria levels of midwifery students and the factors affecting them in the Covid-19 Pandemic. 
Method: The sample of the study, which was conducted in a descriptive design, consisted of 308 students studying at the Department of Midwifery in the Faculty of Health Sciences of a public university (Participation Rate: 93\%). "Personal Information Form"and "Cyberchondria Severity Scale (CSS)" were applied to the students who accepted to participate in the study.

Results: It was determined that the mean age of the students participating in the study was $20.96 \pm 2.56$. It was determined that $14.6 \%$ of the midwife candidates were diagnosed with Covid-19 infection, $71.8 \%$ had contact with an individual who had Covid-19, and $36.7 \%$ had a family member diagnosed with Covid-19. It was determined that the total mean score of the students on the Cyberchondria Severity Scale was $77.44 \pm 23.01$. It was determined that the students' grade level, smoking status, presence of chronic disease, Covid-19 infection, and the presence of a family member with Covid-19 infection significantly differentiated their SCS scores.

Conclusions and Suggestions: It was determined that the students participating in the study had moderate cyberchondria. It was determined that variables such as class level, smoking status, presence of chronic disease, Covid-19 infection and the presence of an individual with a family history of Covid-19 infection were important predictors of cyberchondria behavior. To minimize cyberchondria in midwifery students, an effective plan should be developed to combat this new danger by addressing the increased threat perception and improving uncertainty management and online health information literacy.

Keywords: Midwifery; Students; Covid-19; Cyberchondria; Pandemic

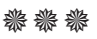

$$
\begin{aligned}
& \text { GíRiş }
\end{aligned}
$$

Covid-19 enfeksiyonu, dünya nüfusu üzerinde ani ve geniş çaplı hastalık ve ölüme yol açarak, 21. yüzyılın en büyük küresel halk sağlığı krizinin yaşanmasına neden olmuştur (World Health Organization/WHO, 2020). Tüm dünyada hizla yayınlan Covid-19 enfeksiyonu (SARSCoV2) Dünya Sağlık Örgütü (DSÖ) tarafindan 11 Mart 2020 tarihinde pandemi olarak ilan edilmiştir (WHO, 2020). Covid-19 pandemisi yaklaşık beş milyon insanın ölümüne sebep olurken, 200 milyon vaka sayısı ile birçok sağlık sorunun yaşanmasına, tüm dünyada sağlık sistemlerinin büyük stres altına girmesine ve pek çok ülkede ise çökmesine sebep olmuştur (Worldometers, 2021).

Pandeminin ilanı kaygı ve stres düzeyinin artmasına neden olmuştur (Wang et 
al., 2020).Sosyal yaşam değişirken çevrimiçi bilgi ve bilgiye ulaşma hızla artmıştır (Starcevic et al., 2020). Artan bilgi ve bilgiye erişimin kolaylı̆̆ hasta ve sağlıklı popülasyonda bir takım psikolojik sorunları beraberinde getirmektedir (Wu et al., 2021). İnsanların sağlık ile ilgili konularda endişelenme ve bu endişe durumunu azaltma isteği, bir takım arayışlar içerisinde olmasına neden olmuştur. Bu noktada ulaşılabilirliği kolay ve hızlı bir tıbbi değerlendirme yapılabilmesine olanak tanıyan internetten hastalık arama davranışı gerçekleştirilmektedir. Sağlık anksiyetesi ile bireyin internetten hastalık arama davranışı siberkondri olarak tanımlanmaktadır(Vismara et al., 2020). Starcevic ve Berle ise siberkondriyi, "sağlıkla ilgili anksiyete veya endişeden kaynaklanan, internette aşırı veya tekrarlayan bir şekilde sağlıkla ilgili bilgi arama sonucu anksiyete veya endişenin artması” olarak tanımlamıştır (Starcevic \& Berle, 2013). Ve bu durum fayda vermeyip sağlık sonuçlarının kötüleşmesine neden olabilmektedir (Altındiş ve ark., 2018). Kendisinde var olmayan semptomları var sayma ve ya aşırı semptom geliştirmek sağlık konusundaki kaygıları arttırabilmektedir (Erdoğan \& Hocaoğlu, 2020).

Hastalık ile ilgili korkular sosyal ağlar ile yayılırken hastalık kadar tehlike göstermektedir (Jokic-Begic et al., 2020). Bireylerin siberkondri düzeylerini azaltmak için arama motorlarında ve sosyal medyada pandemi hakkında doğru bilgilerin yayınlanmasının yararlı olabileceği bildirilmiştir (Jungmann \& Witthöft, 2020). Covid-19 pandemisinde evde kal çağrısı ile insanların çevirimçi platformları kullanma oranları artmıştır (King et al. 2020). Öğrenciler çevirimiçi platformları yetişkinlere oranla daha fazla kullanmaktadır. Kendilerine uzman görüşü almadan tanı koyabilmektir. Bu da ruhsal açıdan bireyler için yıkıcı sonuçlara neden olmaktadir.

İnternetin giderek yaygınlaşan kullanımı ve çevrimiçi tıbbi bilgileri görüntülemenin olası olumsuz etkileri göz önüne alındığında, siberkondri önemli bir halk sağlığı sorunudur. Siberkondri risk durumlarının belirlenmesi, gerekli yönlendirmelerin yapılması önemlidir. Bununla birlikte, bu fenomenle ilgili araştırmalar sürdürülmektedir ve toplum üzerindeki etkilerini belirlemek için çalışmaların yapılmasına ihtiyaç vardır. Bu çalışma, Covid-19 salgınında ebelik öğrencilerinin siberkondri düzeyleri ile etkileyen faktörlerin belirlenmesi amacıyla planlanmıştır.

\section{YÖNTEM}

Tanımlayıcı desende yürütülen çalışmanın evrenini bir kamu üniversitesinin Sağlık Bilimleri Fakültesi Ebelik Bölümü birinci ve ikinci, üçüncü, dördüncü sınıfinda öğrenim gören öğrenciler oluşturdu (N:357). Çalışmada örneklem seçimine gidilmemiş olup, çalışmaya gönüllü olarak katılmayı kabul eden 308 öğrenci çalışmanın örneklemini oluşturdu (Katılma Oranı: \%93). 


\section{Veri Toplama Formları}

Veri toplama formları uygulanmaya başlamadan önce, araştırmaya katılan öğrenciler ile "Bilgilendirilmiş Gönüllü Onam Formu" paylaşılıp, online olarak onaylamaları talep edildi. Çalışmaya katılmayı kabul eden öğrencilere, "Kişisel Bilgi formu" ve "Siberkondri Ciddiyet Ölçeği" uygulanmıştır.

\section{Kişisel Bilgi Formu}

Araştırmacılar tarafından geliştirilen form, ebelik öğrencilerinin sosyo-demografik özelliklerini (yaş, bölümü, sınıfı, aile tipi, sosyo-ekonomik durumu vb.), genel sağlık öyküsünü (kronik hastalık varlığı, sigara kullanımı vb.), Covid-19 pandemisi ile ilgi bilgi ve tutumlarını belirlemek amacı ile oluşturulmuştur.

\section{Siberkondri Ciddiyet Ölçeği}

McElroy ve Shevlin tarafından (2014) geliştirilmiş, Uzun ve ark. tarafından (2016) Türkçe Geçerlik güvenirlik çalışması yapılmış 33 maddeli, 5’li likert tipi (Hiç: 1 puan ve Her zaman: 5 puan) ve beş boyutlu bir ölçme aracıdır. Bu beş boyut; zorlantı, aşırı kaygı (distress), aşırılık, içini rahatlatma ve doktora güvensizliktir. Zorlantı alt boyutu 3.,6.,8.,12.,14.,17.,24.,25., aşırı kayg1 alt boyutu 5.,7.,10.,20.,22.,23.,29.,31., aşırılık alt boyutu 1.,2.,11.,13.,18.,19.,21.,30., içini rahatlatma alt boyutu 4.,15.,16.,26.,27.,32., doktora güvensizlik alt boyutu 9.,28.,33. sorulardan oluşmaktadır. Siberkondri ciddiyet ölçeğinde 9, 28 ve 33 numaralı sorular tersten puanlanmaktadır. Ölçekten 33-165 arası puan alınabilmektedir. Ölçekten alınan puanların yüksekliği, siberkondri şiddetinin de yüksekliğini göstermektedir. Uzun ve ark.'nın (2016) çalışmasında ölçeğin toplam Cronbach Alpha Değeri 0.89 ve alt boyutlarının Cronbanch Alpha Değeri 0.65 ile 0.85 arasında bulunmuştur. Bu çalışma için Cronbach Alfa iç tutarlık katsayısı değeri 0.72’dir.

\section{Verilerin toplanması}

Araştırma, 2020-2021 Eğitim Öğretim yılı Bahar döneminde yürütülmüştür. Veriler, araştırmanın yapıldığı Sağlık Bilimleri Fakültesi'nde bulunan, araştırma hakkında bilgi verilen ve araştırmaya katılmayı gönüllü olarak kabul eden, bilgilendirilmiş onamları alınan öğrencilerden https:/www.google.com/forms/about/ isimli link bağlantılı İnternet uygulaması ile toplanmıştır. Öğrencilere çalışmanın anketinin linki online olarak (mail, whatsapp vb.) öğrenci temsilcileri aracılığıla ulaştırılmıştır. 


\section{Verilerin Değerlendirilmesi}

Araştırma verileri, SPSS 16.0 (Statistical Package for Social Science) paket programında değerlendirilmiştir. Verilerin değerlendirilmesinde, tanımlayıcı istatistiksel analizlerinden sayı, yüzde, ortalama ve standart sapma kullanılmıştır. Verilerin dağılımı Kolmogorov Smirnov testi ile kullanılarak değerlendirilmiştir. Ölçek puanları arasındaki ilişkinin incelenmesinde; Spearman korelasyon analizi kullanılmıştır. İki kategori içeren kategorik değişkenlerle nicel değişkenlerin karşılaştırılmasında Mann-Whitney U testi, ikiden çok kategori içeren değişkenlerle nicel değişkenlerin karşılaştırılmasında Kruskal Wallis H testi kullanılmıştır. Kruskal Wallis $\mathrm{H}$ testi neticesinde farklılık tespit edilmesi durumunda; kategoriler Mann-Whitney U testi ile ikişerli olarak karşılaştırılarak farklılığın hangi kategori ya da kategorilerden kaynaklandığı tespit edilmiştir. 0,05 in altındaki "p" değerleri istatistiksel olarak anlamlı kabul edilmiştir.

\section{Etik ilkeler}

Araştırmanın yapılabilmesi için Sağlık Bilimleri Üniversitesi Hamidiye Bilimsel Araştırmalar Etik Kurulu’ndan (Sayı: E-46418926-050.01.04-40281) ve araştırmanın yapıldığ tır. Araştırmaya dahil edilecek öğrencilere çalışma hakkında bilgi verilerek online olarak onamları alınmıştır.

\section{BULGULAR}

Araştırma kapsamındaki öğrencilerinin yaş ortalamasının $20.96 \pm 2.56$ (min:20, max:29) olduğu, \%30.5'unun birinci, \%23.4'nün ikinci, \%26'sının üçüncü ve \%20 .1'nin ise dördüncü sınıf olduğu belirlendi. Ebelik öğrencilerinin çoğunlukla ilde yaşadığı (\%64.9) ve gelirinin giderine denk (\%64.9) olduğu belirlendi (Tablo 1).

\begin{tabular}{|c|c|c|}
\hline \multicolumn{3}{|l|}{ Sosyodemografik Özellikler } \\
\hline & Ort \pm SS & Min-Max \\
\hline \multirow[t]{2}{*}{ Yaş } & $20.96 \pm 2.56$ & $(18-37)$ \\
\hline & $\mathbf{n}$ & $\%$ \\
\hline \multicolumn{3}{|l|}{ Sinif } \\
\hline 1. Sinif & 94 & 30.5 \\
\hline 2. Sinif & 72 & 23.4 \\
\hline 3. Sinif & 80 & 26.0 \\
\hline 4. Sinif & 62 & 20.1 \\
\hline \multicolumn{3}{|l|}{ Çoğunlukla yaşadığı yer } \\
\hline Köy & 19 & 6.2 \\
\hline İlçe & 89 & 28.9 \\
\hline İl & 200 & 64.9 \\
\hline \multicolumn{3}{|l|}{\begin{tabular}{|l|} 
Gelir Durumu \\
\end{tabular}} \\
\hline Gelirim Giderimden Fazla & 23 & 7.5 \\
\hline
\end{tabular}




\begin{tabular}{|c|c|c|}
\hline Gelirim Giderime Denk & 200 & 64.9 \\
\hline Gelirim Giderimden az & 85 & 27.6 \\
\hline \multicolumn{3}{|l|}{ Sigara kullanımı } \\
\hline Evet & 41 & 13.3 \\
\hline Hayır & 267 & 86.7 \\
\hline \multicolumn{3}{|l|}{ Alkol Kullanımı } \\
\hline Evet & 28 & 5.8 \\
\hline Hayır & 290 & 94.2 \\
\hline \multicolumn{3}{|l|}{ Kronik hastalık durumu } \\
\hline Evet & 23 & 7.5 \\
\hline Hayır & 285 & 92.5 \\
\hline
\end{tabular}

Çalışmaya katılan öğrencilerin büyük çoğunluğunun sigara ve alkol kullanmadığ 1 belirlenirken, \%7.5'nun bir kronik hastalığı olduğu belirlendi (Tablo 1). Kronik hastalıklar arasında; \%3 astım, \%1 hipotroidi, \%1 hipertansiyon, \%1 böbrek yetmezliği, \%0.6 diyabet, \% 0.6 polikistik over sendromu ve \%0.3 ise Crohn hastalığı yer aldığı saptanmıştır.

\section{Tablo 2. Öğrencilerin Covid-19 Enfeksiyonu İle İlgili} Deneyim ve Tutumları (n:308)

\begin{tabular}{|c|c|c|}
\hline & $\mathbf{n}$ & $\%$ \\
\hline \multicolumn{3}{|c|}{ Covid-19 enfeksiyonu geçirdiniz mi } \\
\hline Evet & 45 & 14.6 \\
\hline Hayır & 263 & 85.4 \\
\hline \multicolumn{3}{|c|}{ Ailenizde Covid-19 tanısı alan birey mevcut mu } \\
\hline Evet & 221 & 71.8 \\
\hline Hayır & 87 & 28.2 \\
\hline \multicolumn{3}{|c|}{ Covid-19 enfeksiyonu olan birey ile temas durumu } \\
\hline Evet & 113 & 36.7 \\
\hline Hayır & 195 & 63.3 \\
\hline \multicolumn{3}{|c|}{ Covid 19 pandemisi için yeterince önlem durumu } \\
\hline Evet & 260 & 84.4 \\
\hline Hayır & 48 & 15.6 \\
\hline \multicolumn{3}{|c|}{ Çevrimiçi platformlarda geçirilen günlük süre } \\
\hline $0-30$ & 79 & 22.4 \\
\hline $30 \mathrm{dk}-1$ saat & 65 & 21.1 \\
\hline $1-2$ & 27 & 8.8 \\
\hline $1-4$ saat & 69 & 25.6 \\
\hline 4 saat ve üzeri & 68 & 22.1 \\
\hline \multicolumn{3}{|c|}{${ }^{\star}$ Covid-19 hakkında güncel bilgi takibi aracı } \\
\hline İnternet & 307 & 99.7 \\
\hline Sosyal medya & 285 & 92.5 \\
\hline Televizyon & 272 & 88.3 \\
\hline
\end{tabular}




\begin{tabular}{|l|c|c|}
\hline Çevre & 116 & 37.7 \\
\hline Sağlık çalışanı & 112 & 36.4 \\
\hline
\end{tabular}

Covid-19 Pandemisinin bitip eski hayat düzenine döneceğine inaniyor musunuz

\begin{tabular}{|l|c|c|}
\hline Evet & 94 & 30.5 \\
\hline Hayır & 83 & 26.9 \\
\hline Kismen & 131 & 42.5 \\
\hline ×
\end{tabular}

*Covid 19 pandemisine karşı en çok hangi önleme dikkat ediyorsunuz

\begin{tabular}{|l|c|c|}
\hline Sosyal İzolasyon & 215 & 69.8 \\
\hline Maske Kullanımı & 307 & 99.7 \\
\hline Hijyen Kuralları & 212 & 68.8 \\
\hline Sağlıkı Beslenme & 181 & 58.8 \\
\hline Vitamin Desteği & 62 & 20.1 \\
\hline Egzersiz & 58 & 18.8 \\
\hline Covid-19 pandemisinin yaşam kalitenizi değiştirdi mi \\
\hline Evet & 219 & 71.1 \\
\hline Hayır & 12 & 3.9 \\
\hline Kısmen & 77 & 25 \\
\hline
\end{tabular}

*Birden fazla yanıt verilmiştir

Katılımcıların \%14.6'sı polimeraz zincir reaksiyonu (PCR) ile doğrulanan bir COVID-19 enfeksiyonu öyküsü bildirdi. Ebelik öğrencilerinin \%36.7’si COVID-19 geçiren birey ile temas ettiğini bildirirken, \%71.8'inin ailesinde PCR ile doğrulanmış Covid-19 tanısı alan birey olduğu belirlendi (Tablo 2).

Öğrencilerin Covid-19 pandemisi ile ilgili güncel haberleri takip etmek için çevrimiçi platformlarda geçirdiği sürenin çoğunlukla 1-4 saat (\%25.6) olduğu, bu haberleri daha çok internet (\%99.7) ve sosyal medya (\%92.5) araçları ile takip ettikleri belirlendi. Öğrencilerin Covid-19 pandemisi için aldıkları önlemler arasında çoğunlukla maske (\%99.7), sosyal izolasyon(\%69.7), hijyen kuralları (\%68.8) ve sağlıklı beslenme (\%58.8) olduğu belirlendi (Tablo 2).

Çalışmaya katılan ebe adaylarının çoğunluğunun Covid-19 pandemisinin yaşam kalitesini etkilediği (\%71.1) ve Covid-19 pandemsinin bitip eski hayat düzenine döneceğine kısmen (\%42.5) inandıkları belirlendi (Tablo 2).

Tablo 3. Siberkondri Ciddiyet Ölçeği Toplam Puan ve Alt Boyut Puan Ortalamalarının Dağılımı

\begin{tabular}{|l|c|c|}
\hline Siberkondri Ciddiyet Ölçeği & Min-Max değer & Ort \pm SS \\
\hline Zorlantı & $8-40$ & $13.83 \pm 7.10$ \\
\hline Aşırı Kaygı & $8-40$ & $18.33 \pm 7.14$ \\
\hline Aşırılık & $8-40$ & $23.50 \pm 6.98$ \\
\hline
\end{tabular}




\begin{tabular}{|l|c|c|}
\hline İçini Rahatlatma & $6-30$ & $15.33 \pm 5.65$ \\
\hline Doktora Güvensizlik & $3-15$ & $6.43 \pm 3.0$ \\
\hline Toplam puan & $39-153$ & $77.44 \pm 23.01$ \\
\hline
\end{tabular}

Çalışmaya katılan ebe adaylarının Siberkondri Ciddiyet Ölçeği toplam puan ortalamas1 77.44 23.01 (min:39, max:153) olarak belirlendi.

Tablo 4. Öğrencilerin Sosyo-Demografik Ve Bazı Özelliklerine Göre SCÖ Toplam Puan ve Alt Boyutları Puan Ortalamalarının Karşılaştırılması (n:308)

\begin{tabular}{|c|c|c|c|c|c|c|c|}
\hline & \multirow{3}{*}{$\begin{array}{c}\begin{array}{c}\text { SCÖ } \\
\text { Zorlantı } \\
\text { Alt Boyutu }\end{array} \\
\text { Ort } \pm \text { SS }\end{array}$} & \multirow{3}{*}{$\begin{array}{c}\text { SCÖ Aşırı } \\
\text { Kaygı } \\
\text { Alt Boyutu } \\
\text { Ort } \pm \text { SS }\end{array}$} & \multirow{3}{*}{$\begin{array}{c}\text { SCÖ } \\
\text { Assirilık } \\
\text { Alt Bo- } \\
\text { yutu }\end{array}$} & \multirow{3}{*}{$\begin{array}{c}\begin{array}{c}\text { SCÖ İcini } \\
\text { Rahatlat- } \\
\text { ma } \\
\text { Alt Boyutu }\end{array} \\
\text { Ort } \pm \text { SS }\end{array}$} & \multirow{3}{*}{$\begin{array}{c}\text { SCÖ } \\
\text { Doktora } \\
\text { Güvensiz- } \\
\text { lik } \\
\text { Alt Bo- } \\
\text { yutu } \\
\text { Ort } \pm \text { SS }\end{array}$} & \multirow{3}{*}{$\begin{array}{c}\text { SCÖ Top- } \\
\text { lam Puan } \\
\text { Ortalamas1 } \\
\text { Ort } \pm \text { SS }\end{array}$} \\
\hline & & & & & & & \\
\hline & & & & & & & \\
\hline \multirow{6}{*}{$\begin{array}{l}\text { Sinıf Dü- } \\
\text { zeyi }\end{array}$} & $\begin{array}{l}1 . \\
(\mathrm{n}: 94) \mathrm{a}\end{array}$ Sinıf & $14.73 \pm 7.82$ & $19.34 \pm 6.96$ & $24.83 \pm 6.86$ & $16.34 \pm 5.23$ & $6.38 \pm 2.89$ & $81.65 \pm 23.30$ \\
\hline & $\begin{array}{l}2 . \\
(\mathrm{n}: 72) b\end{array}$ Sinıf & $12.27 \pm 5.71$ & $17.17 \pm 6.34$ & $22.98 \pm 6.76$ & $15.12 \pm 5.36$ & $6.36 \pm 3.12$ & $73.92 \pm 19.35$ \\
\hline & $\begin{array}{l}3 . \\
(\mathrm{n}: 80) c\end{array}$ Sinıf & $13.78 \pm 6.69$ & $18.63 \pm 7.13$ & $23,33 \pm 6.92$ & $14.48 \pm 5.81$ & $6.26 \pm 2.77$ & $76.51 \pm 23.46$ \\
\hline & $\begin{array}{l}4 . \\
(\mathrm{n}: 62) d\end{array}$ Sinıf & $15.20 \pm 8.28$ & $18.54 \pm 8.36$ & $22.95 \pm 7.47$ & $15.58 \pm 6.23$ & $6.80 \pm 3.26$ & $79.09 \pm 23.54$ \\
\hline & & ${ }^{*} \mathrm{p}: 036$ & ${ }^{*} \mathrm{p}: .052$ & ${ }^{*} \mathrm{p}: .059$ & ${ }^{*} \mathrm{p}: .131$ & ${ }^{*} \mathrm{p}: .772$ & ${ }^{*} \mathrm{p}: .043$ \\
\hline & & $\mathbf{a}>\mathbf{b}$ & & & & & $\mathbf{a}>\mathbf{b}$ \\
\hline \multirow{4}{*}{$\begin{array}{l}\text { Gelir du- } \\
\text { rumu }\end{array}$} & $\begin{array}{l}\text { Gelirim } \\
\text { giderimden } \\
\text { az } \\
(\mathrm{n}: 23)\end{array}$ & $14.04 \pm 8.15$ & $17.21 \pm 6.31$ & $23.91 \pm 6.12$ & $17.34 \pm 4.49$ & $5.82 \pm 2.34$ & $78.34 \pm 23.03$ \\
\hline & $\begin{array}{l}\text { Gelirim gide- } \\
\text { rime } \\
\text { denk (n:200) }\end{array}$ & $13.46 \pm 6.94$ & $18.03 \pm 7.29$ & $23.45 \pm 7.13$ & $14.97 \pm 5.81$ & $6.53 \pm 3.08$ & $76.45 \pm 22.97$ \\
\hline & $\begin{array}{l}\text { Gelirim } \\
\text { giderimden } \\
\text { fazla }(\mathrm{n}: 85)\end{array}$ & $14.64 \pm 7.20$ & $19.35 \pm 6.97$ & $23.51 \pm 6.91$ & $15.64 \pm 5.45$ & $6.36 \pm 2.97$ & $79.52 \pm 23.21$ \\
\hline & & ${ }^{*} \mathrm{p}: .340$ & ${ }^{*} \mathrm{p}: .238$ & ${ }^{*} \mathrm{p}: .944$ & *p:.097 & ${ }^{*} \mathrm{p}: .721$ & ${ }^{*} \mathrm{p}: .539$ \\
\hline \multirow{3}{*}{$\begin{array}{l}\text { S i g a r a } \\
\text { kullanma } \\
\text { durumu }\end{array}$} & Evet(n:113) & $19.73 \pm 10.16$ & $22.80 \pm 8.82$ & $27.68 \pm 7.68$ & $19.58 \pm 6.13$ & $6.02 \pm 2.38$ & $95.82 \pm 30.20$ \\
\hline & $\begin{array}{l}\text { Hayır } \quad(n: \\
195)\end{array}$ & $12.92 \pm 6.05$ & $17.65 \pm 6.61$ & $22.86 \pm 6.65$ & $14.68 \pm 5.29$ & $6.49 \pm 3.09$ & $74.62 \pm 20.34$ \\
\hline & & ${ }^{* *} \mathrm{p}: .000$ & ${ }^{* *} \mathrm{p}: .000$ & ${ }^{* *} \mathrm{p}: .000$ & ${ }^{* *} \mathrm{p}: .000$ & ${ }^{* *}$ p:.625 & ${ }^{* *} \mathrm{p}: .000$ \\
\hline
\end{tabular}




\begin{tabular}{|c|c|c|c|c|c|c|c|}
\hline \multirow{3}{*}{$\begin{array}{l}\text { K ron i k } \\
\text { hastalığa } \\
\text { s a h i p } \\
\text { olma } \\
\text { durumu }\end{array}$} & Evet(n:113) & $17.34 \pm 9.24$ & $21.86 \pm 9.03$ & $26.26 \pm 7.78$ & $17.43 \pm 6.50$ & $6.34 \pm 2.99$ & $89.26 \pm 29.22$ \\
\hline & $\begin{array}{l}\text { Hayır } \quad(\mathrm{n}: \\
195)\end{array}$ & $13.55 \pm 6.85$ & $18.05 \pm 6.91$ & $23.28 \pm 6.88$ & $15.16 \pm 5.55$ & $6.43 \pm 3.01$ & $76.49 \pm 22.22$ \\
\hline & & ${ }^{* *}$ p.. 112 & ${ }^{* *} \mathrm{p}: .040$ & ${ }^{* *}$ p:.045 & ${ }^{* *} \mathrm{p}: .067$ & ${ }^{* *}$ p:.920 & ${ }^{* *}$ p:.035 \\
\hline \multirow{2}{*}{$\begin{array}{l}\text { Covid - } \\
19\end{array}$} & Evet (n:45) & $14.98 \pm 8.51$ & $20.43 \pm 7.87$ & $25.62 \pm 6.81$ & $17.33 \pm 6.05$ & $6.09 \pm 2.43$ & $84.47 \pm 25.10$ \\
\hline & Hayır (n:263) & $13.59 \pm 6.77$ & $17.90 \pm 6.92$ & $23.06 \pm 6.95$ & $14.92 \pm 5.48$ & $6.50 \pm 3.11$ & $75.98 \pm 22.32$ \\
\hline $\begin{array}{l}\text { enfeksi- } \\
\text { yon } \\
\text { geçirme } \\
\text { durumu }\end{array}$ & & ${ }^{* *} \mathrm{p}: .497$ & ${ }^{* *}$ p:.039 & ${ }^{* *}$ p:.016 & ${ }^{* *} \mathrm{p}: .012$ & **p:.707 & ${ }^{* *}$ p:.025 \\
\hline \multirow{2}{*}{$\begin{array}{l}\text { Ailede } \\
\text { C ov i d - } \\
19 \text { tanisi }\end{array}$} & $\operatorname{Evet}(n=221)$ & $13.24 \pm 6.65$ & $17.58 \pm 6.55$ & $23.12 \pm 6.82$ & $15.07 \pm 5.51$ & $6.40 \pm 3.02$ & $75.44 \pm 21.80$ \\
\hline & Hayır $(n=87)$ & $15.98 \pm 8.28$ & $21.10 \pm 8.48$ & $24.89 \pm 7.43$ & $16.28 \pm 6.08$ & $6.51 \pm 2.97$ & $84.78 \pm 25.85$ \\
\hline $\begin{array}{l}19 \text { tanısı } \\
\text { alan bi- } \\
\text { reyva r- } \\
\text { lığı } \\
\text { durumu }\end{array}$ & & ${ }^{* *}$ p:.690 & ${ }^{* *} \mathrm{p}: .035$ & ${ }^{* *} \mathrm{p}: .101$ & **p:.076 & ${ }^{* *}$ p:.597 & ${ }^{* *} \mathrm{p}: .063$ \\
\hline
\end{tabular}

${ }^{\star}$ Kruskal Wallis Test,${ }^{*}$ Mann Whitney U Test

Öğrenci ebelerin sınıf düzeyine göre SCÖ zorlantı alt boyut puan ortalaması ve ölçek toplam puan ortalamasının anlamlı olarak farklılaştığ belirlenirken, gelir durumu değişkenine göre SCÖ ölçek puanlarının anlamlı olarak farklılaşmadığı belirlendi.

Öğrencilerin sigara kullanma durumu, SCÖ toplam puan ortalamaları ve zorlantı, aşırı kaygı, aşırılık, içini rahatlatma alt boyut puan ortalamalarını anlamlı olarak farklılaştırırken, kronik hastalık varlığı ise SCÖ toplam puan, aşırı kaygı ve aşırılık alt boyut puan ortalamalarını anlamlı olarak farklılaştırdığı belirlendi.

Covid-19 enfeksiyonu geçirme durumu SCÖ toplam puan, aşırı kaygı, aşırılık ve içini rahatlatma alt boyut puan ortalamalarını farklılaştırırken, ailesinde Covid-19 enfeksiyonu geçiren birey olma durumunun ise sadece SCÖ aşırı kaygı alt puan ortalamasını farklılaştırdığı saptandı (Tablo 4).

\section{TARTIŞMA}

Bu çalışmada, Covid-19 pandemisinde ebelik öğrencilerinin siberkondri düzeyleri ve etkileyen faktörler incelenmiştir. Çalışmaya katılan ebe adaylarının Si-

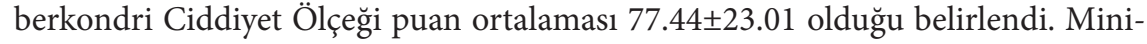
mum (33 puan), maksimum (165 puan) değerler göz önüne alındığında, çalışmaya katılan öğrencilerde orta düzeyde siberkondri saptanmıştır. Digital çağın yeni 
kavramlarından olan siberkondri ile ilgili ulusal ve uluslararası literatürde yapılan çalışmalar oldukça sınırlıdır. Norr ve ark.'nın 2015 yılında bir internet sitesini kullanan 526 kişide yaptığı çalışmada orta düzeyde siberkondri saptarken (Norr ve ark., 2015), Barke ve ark.'nın (2016) Almanya'da internet üzerinden 500 kişide yaptıkları çalışmada ise siberkondri puanları ort:60,0 olarak bildirilmiştir (Barke ve ark., 2016).

Çalışma sonuçlarımızla benzer şekilde Apay ve ark.'nın (2017) bir üniversitede 411 öğrenci ile yaptıkları çalışmada (2017) siberkondri ölçek puan ortalama-

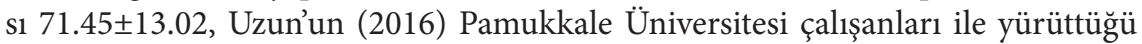
çalışmada siberkondri toplam puan ortalaması ise $71.1 \pm 17.6$ olarak bulunurken, Tüter'in aile hekimliği polikliniğine başvuran bireylerde ve Başoğlu'nun 15-49 yaş gurubu kadın hastalarla yaptığı çalışmada ise siberkondri düzeyi orta şiddette olduğu bulunmuştur (Apay ve ark., 2017; Uzun, 2016; Tüter, 2019; Başoğlu, 2018). Ebelik öğrencilerin siberkondri düzeyleri toplum ortalaması ile benzerdir. Pandemi gibi olağanüstü durumlarda hastalık hakkında daha fazla bilgi öğrenmek sağlık anksiyetesini artırarak siberkondri davranışını tetikleyebilir. Dolayısıyla Covid-19 pandemisinin öğrencilerin siberkondri düzeylerini etkilediği düşünülmektedir. Ebe adaylarına mesleki eğitimleri süresince sağlık okuryazarlığ 1 bilinci kazandırılarak gereksiz sağlık kaygısı ile beslenen siberkondri davranışı azaltılabilir veya önlenebilir.

Çalışma bulgularına göre birinci sınıf öğrencilerin ikinci sınıf öğrencilere göre siberkondri tutumlarının daha yüksek olduğu belirlendi. Mesleki eğitim düzeyi artıkça siberkondri davranışının azaldığı görülmüştür. Çalışma kapsamında yer alan öğrenciler teknolojiye adaptasyonu yüksek Z kuşağıdır. Dolayısıyla, sağlıkla ilgili bilgilere kolayca erişim sağlamaktadırlar. İnternet, tıbbi bilgilere ve kayıtlara insanların erişimini sağlayan önemli bir sağlık bilgi kaynağı olmasının yanında güvenli bir bilgi kaynağı olup olmadığı tartışmalıdır. Nitekim, sağlıkla ilgili internet sitelerini inceleyen çalışmalar, bilgilerin güvenilirliği, kalitesi ve doğruluğu konusunda sorunlar olduğunu bildirmektedir. Özellikle kaynağı konusunda netlik bulunmayan bilgiler, kişilerin sağlık davranışlarında ve dolayısıyla sağlık durumlarında olumsuz sonuçlara neden olabilmektedir (Yılmaz, 2014). Bu nedenle, toplum sağlığına olumsuz etki edebilecek bilgi kaynaklarının önüne geçebilen çeşitli düzenlemelerin varlığı zorunlu hale gelmektedir.

Çalışmaya katılan öğrencilerin \%22.1'i Covid-19 pandemisi ile ilgili güncel durumu takip etme ve hastalık hakkında bilgi sahibi olmak için günde " 4 saat ve üzeri” internette zaman geçirdiği belirlenmiştir. Öğrenciler, arama motorlarını kullanarak kolaylıkla internetteki aşırı miktardaki filtresiz sağlık bilgisine ulaşmaktadır. İnternetteki teknik dil, kaliteli bilgi eksikliği ve olumsuz bilgi bolluğu gibi durumlar, kişilerde sağlık kaygısını artırmaktadır (White \& Horvitz, 2009). 
Dolayısıyla, digital ortamda sağlık bilgisi arama davranışının artmasının bir sonucu olarak siberkondri insidansının da artması beklenmektedir (Bati et al., 2018). Sağlık okuryazarlık düzeyinin tüm kuşaklarda "dijital sağlık okuryazarlığı” olarak güncellenerek başta Z kuşağına ve eğitimcilere olmak üzere tüm kuşaklara uygulanabilirliğinin sağlanması oldukça önemlidir.

Çalışma bulgularına göre sigara kullanma durumu veya kronik hastalığı varlığı siberkondrik tutumu artıran değişkenler olduğu saptanmıştır. Çalışma bulgularımızla benzer şekilde, Bati ve ark.'nın (2018) sağlık alanında okuyan 874 öğrenci ile yürüttükleri çalışmada öğrencilerde sağlık sorunu varlığının siberkondri üzerinde etkili olduğunu bildirmişlerdir (Bati ve ark., 2018). Küresel bir halk sağlığ1 krizi olan Covid-19 enfeksiyonu için kronik rahatsızlıkları bulunanların risk altında olduğu bildirilmektedir (Akpinar \& Ustun, 2020). WHO'ya göre (2020) bağ $1 s ̧ ı$ klığ zayıf kişiler, kalp rahatsızlıkları olan kişiler, astımlı kişiler, obezitesi olan kişiler, HIV, karaciğer ve böbrek hastalığı olan kişiler yüksek risk grubunda yer almaktadır. Ayrıca, tütün kullanımının da Covid-19 salgınının ağırlaştırıcı faktörleri arasında olduğu bildirilmiştir (Halk Sağlığı Uzmanları Derneği/HASUDER, 2020). Dolayısıyla riskli grupta bulunan öğrenciler, virüs bulaşmasına yönelik artan kaygı düzeyi ile birlikte sosyal medya ve internet üzerinden hastalığa ilişkin araştırma yaparak kendini rahatlama davranışları sergileyebilirler. Siberkondriye sahip bireylerin, internetin yalnızca sağlıkla ilgili bilgi edinmenin bir yolu olduğunu ve sağlıkla ilgili tüm soruların cevaplarını bulunduran ve kendi kendine tanı koyabilmesini sağlayan bir araç olmadığını öğrenmeleri gereklidir (Starcevic, 2013).

Tüm dünyayı etkisi altına alan Covid-19 salgının hızlı yayılması, henüz bir tedavisinin olmaması ve ölümcül seyretmesi üniversite öğrencilerinin ruh sağl1ğ1 üzerinde olumsuz etkilere neden olabilmektedir. Covid-19 enfeksiyonu geçiren öğrencilerin siberkondri düzeylerinin anlamlı olarak daha yüksek olduğu belirlenirken, ailesinde Covid-19 enfeksiyonu geçiren birey bulunan öğrencilerin ise siberkondri aşırı kaygı alt boyut puan ortalamaları anlamlı olarak yüksek bulunmuştur. Pandemi düzeyindeki salgın hastalıklar; belirsizlik, ölümler ve kalıcı etkilere neden olmaktadır. Bireylerde bulaş riskini azaltmak için sosyal izolasyon ve karantina önlemler uygulanmaktadır. İzolasyon ve karantina yöntemleri salgının yayılmasını engellerken, bireylerin evde geçirdikleri süre artmakla birlikte internette geçirilen süre de artmaktadır. Pandemi süreci ile ilgili belirsizliğinin devam etmesi, yakınını kaybetme riski, henüz bir tedavi yönteminin bulunmaması gibi durumlar Covid-19 enfeksiyonu tanısı alan veya ailesinde Covid-19 tanısı alan birey bulunan öğrencilerde psikososyal etkilere neden olmaktadır. Bu süreçte, kişisel düzeyde, insanların sağlıkları, aileleri, güvenlikleri veya mali durumları için korku duymaları muhtemeldir (Taylor, 2019).

Covid-19 pandemisinin neden olduğu korku ve belirsizlik ile bu küresel teh- 
dide ilişkin çevrimiçi, doğrulanmamış ve sürekli güncellenen bilgilerin bolluğu, giderek artan bir şekilde önemli halk sağlığı sorunu olarak kabul edilen siberkondrinin gelişimi için verimli bir topraktır. Artan tehdit algısını ele alarak, belirsizlik yönetimini ve çevrimiçi sağlık bilgisi okuryazarlığını geliştirerek bu yeni tehlikeye karşı etkin mücadele planı geliştirilmelidir.

\section{SONUÇ VE ÖNERİLER}

Çalışmaya katılan öğrencilerin orta düzeyde siberkondriye sahip oldukları belirlenmiştir. Öğrencilerin sınıf düzeyi, sigara kullanma durumu, kronik hastalığı varlığ 1 , Covid-19 enfeksiyonu geçirme ve ailesinde Covid-19 enfeksiyonu geçiren birey varlığ 1 gibi değişkenlerin siberkondri düzeyini etkilediği belirlenmiştir.

Her geçen gün artan dijitalleşme ile birlikte sağlık bilgisi arama davranışının zamanla artacağı düşünülmektedir. Sosyal medya platformları ve diğer mecralar aracılı̆̆ıyla hızla yayılan küresel doğrulanmamış bilgi salgını, savunmasız bireyler arasında psikososyal bozukluklarının gelişimi için bir risk faktörü olabilir. Özellikle internet, yanlış ve güvenli olmayan bilgilerle dolup taştı̆̆ bir pandemi durumunda kaygı geliştirmek için bir güvenlik açı̆̆ı faktörüdür. Bu nedenle, bu savunmasız nüfusa daha etkili bir şekilde ulaşmak ve aşırı çevrimiçi arama ve filtresiz bilgilerin zararlı etkilerini önlemek için müdahaleler dijital olarak planlanmalıdır.

Gerek siberkondrinin neden olduğu sağlık problemlerini belirlemek, gerek potansiyel ekonomik maliyetlerinin daha iyi anlaşılmasına katkıda bulunulacak ve bu olumsuz etkileri en aza indirecek stratejilerin belirlenmesi için geniş popülasyonlu çalışmalara ihtiyaç vardır.

\section{Teşekkür ve Açıklamalar}

Araştırmamıza katkı sağlayan tüm öğrencilere teşekkür ederiz.

\section{Çıkar Çatışması}

Yazarlar arasında çıkar çatışması bulunmamaktadır. Finansal destekte bulunan kişi yada kuruluş yoktur.

\section{Yazar Katkısı}

Araştırmanın planlanması: Y.A.K, L.K, veri toplama: L.K, veri analizi: Y.A.K, makale yazımı ve revizyonlar: Y.A.K, L.K 


\section{KAYNAKLAR}

Akpinar, F., \& Üstün, Y. (2020). Current information about SARS-COV-2 (COVID-19) infection in obstetrics and gynecology practice. Turk J Womens Health Neonatol, 2(1), 13-16.

Altındiş, S., Inci, M. B., Aslan, F. G., Altındiş, M. (2018). Üniversite çalışanlarında siberkondria düzeyleri ve ilişkili faktörlerin incelenmesi. Sakarya Tıp Dergisi, 8(2), 359-370. https://doi.org/10.31832/smj.423652.

Apay Ejder, S., Gürol, A., Özdemir, S., Uslu, S. (2019). The reliability and validity of the cyberchondria severity scale for the Turkish students. Çukurova Üniversitesi Eğitim Fakültesi Dergisi, 49(1), 430-450. https://doi. org/10.14812/cufej.571361.

Barke, A., Bleichhardt, G., Rief, W., \& Doering, B. K. (2016). The Cyberchondria Severity Scale (CSS): German Validation and Development of a Short Form. International Journal of Behavioral Medicine, 23(5). https://doi. org/10.1007/s12529-016-9549-8.

Başoğlu, M. A. (2018). Edirne ill Merkezinde 15-49 Yaş Grubu Kadınlarda Siberkondrinin Sürekli Kaygı Ve Psikolojik Iyi Oluş Ille Illişkisinin İncelenmesi. 28-29. Aile Hekimliği Ana Bilim Dalı. Uzmanlık Tezi. Trakya Üniversitesi, Edirne.

Bati, A. H., Mandiracioglu, A., Govsa, F., \& Çam, O. (2018). Health anxiety and cyberchondria among Ege University health science students. Nurse Education Today, 71, 169-173. https://doi.org/10.1016/j.nedt.2018.09.029.

Erdoğan, A., \& Hocaoğlu, Ç. (2020). Siberkondria: Bir gözden geçirme. Psikiyatride Güncel Yaklasimlar, 12(4), 435443. https://doi.org/10.18863/pgy.654648.

Halk Sağlığı Uzmanları Derneği/HASUDER. (2020). https://korona.hasuder.org.tr/wp-content/uploads/ Corona-16.3.2020-11.50.pdf. Erişim Tarihi: 18.06.2021.

Jokic-Begic, N., Korajlija, A. L., \& Mikac, U. (2020). Cyberchondria in the age of COVID-19. PLoS ONE, 15(12), e0243704. https://doi.org/10.1371/journal.pone.0243704.

Jungmann, S. M., \& Witthöft, M. (2020). Health anxiety, cyberchondria, and coping in the current CovID-19 pandemic: Which factors are related to coronavirus anxiety? Journal of Anxiety Disorders, 73, 102239. https:// doi.org/10.1016/j.janxdis.2020.102239.

King, D. L., Delfabbro, P. H., Billieux, J. \& Potenza, M. N. (2020). Problematic online gaming and the CoVID-19 pandemic. Journal of Behavioral Addictions, 9(2), 184-186. https://doi.org/10.1556/2006.2020.00016.

McElroy, E., \& Shevlin, M. (2014). The development and initial validation of the cyberchondria severity scale (CSS). Journal of Anxiety Disorders, 28(2), 259-265. https://doi.org/10.1016/j.janxdis.2013.12.007.

Norr, A. M., Allan, N. P., Boffa, J. W., Raines, A. M., \& Schmidt, N. B. (2015). Validation of the Cyberchondria Severity scale (CSS): Replication and extension with bifactor modeling. Journal of Anxiety Disorders, 31. https://doi. org/10.1016/j.janxdis.2015.02.001.

Starcevic, V. (2013). Hypochondriasis and health anxiety: Conceptual challenges. In British Journal of Psychiatry, 202(1), 7-8. https://doi.org/10.1192/bjp.bp.112.115402.

Starcevic, V., \& Berle, D. (2013). Cyberchondria: Towards a better understanding of excessive healthrelated internet use. Expert Review of Neurotherapeutics, 13(2), 205-213.

Starcevic, V., Schimmenti, A., Billieux, J., \& Berle, D. (2020). Cyberchondria in the time of the COVID-19 pandemic. Human Behavior and Emerging Technologies, 3(1), 53-62. https://doi.org/10.1002/hbe2.233.

Taylor, S. (2019). The Psychology of Pandemics: Preparing for the Next Global Outbreak of Infectious Disease. Newcastle upon Tyne: Cambridge Scholars Publishing.

Tüter, M. (2019). Aile Hekimliği Polikliniğine Başvuran Hastalarda Siberkondri Düzeyinin Ve Illişkili Faktörlerin Değerlendirilmesi. Aile Hekimliği Ana Bilim Dalı. Tıpta Uzmanlık Tezi. Sağlık Bilimleri Üniversitesi, İstanbul.

Uzun, S. U. (2016). Pamukkale Üniversitesi Çalışanlarında Siberkondri Düzeyi ve Etkileyen Etmenler. Halk Sağlığ Ana Bilim Dalı. Uzmanlık Tezi. Pamukkale Üniversitesi, Denizli.

Vismara, M., Caricasole, V., Starcevic, V., Cinosi, E., Dell'Osso, B., Martinotti, G., \& Fineberg, N. A. (2020). Is cyberchondria a new transdiagnostic digital compulsive syndrome? A systematic review of the evidence. In Comprehensive Psychiatry, 99, 152167. https://doi.org/10.1016/j.comppsych.2020.152167.

Wang, C., Pan, R., Wan, X., Tan, Y., Xu, L., Ho, C. S., \& Ho, R. C. (2020). Immediate psychological responses and associated factors during the initial stage of the 2019 coronavirus disease (COVID-19) epidemic among the general population in China. International Journal of Environmental Research and Public Health, 17(5), 1-25. https://doi.org/10.3390/ijerph17051729.

White, R. W., \& Horvitz, E. (2009). Experiences with web search on medical concerns and self diagnosis. AMIA 
Annual Symposium Proceedings, 696-700.

World Health Organization. (2020). WHO Timeline - COVID-19. Erişim adresi: https://www.who.int/news-room/ detail/27-04-2020-who-timeline---covid-19?gclid=EAlalQobChMI4MaewOeo6gIVyyMrCh2JRgUIEAAYASAAE gLo3_D_BwE Erişim tarihi: 30.05.2021.

Worldometers (2021). Worldometer COVID-19 coronavirus pandemic. Erişim adresi: https://www. worldometers. info/coronavirus/ Erişim tarihi: 22.09.2021.

Wu, X., Nazari, N., \& Griffiths, M. D. (2021). Using fear and anxiety related to covid-19 to predict cyberchondria: Cross-sectional survey study. Journal of Medical Internet Research, 23(6). https://doi.org/10.2196/26285.

Yılmaz, E. (2014). Türkiye'de hastaların internette tıbbi enformasyon arama davranışlarının doktor-hasta iletişimine etkileri. Galatasaray Üniversitesi lletişim Dergisi, 93-108. https://doi.org/10.16878/gsuiletişim.12582. 
